DOI:10.5433/1984-7939.2017v2n1p37

\title{
UMA PONTE PARA O FUTURO: POLÍTICAS EDUCACIONAIS E PARCERIAS PÚBLICO-PRIVADAS
}

\author{
Maria Jose Ferreira Ruiz ${ }^{1}$ \\ Kátia Silva Bufalo ${ }^{2}$
}

Resumo: O texto defende que as teses neoliberais e de Terceira Via não são democráticas, embora utilizem do discurso da democracia para empreender suas ações e ganhar legitimidade social. Apesar de apresentarem-se como guardiãs da democracia são contrárias às iniciativas de redistribuição de riquezas e de possibilidade de acesso da classe trabalhadora aos bens econômicos e sociais, por meio de políticas públicas subsidiadas por um Estado provedor. Dessa forma, atualmente muitos dos direitos sociais conquistados historicamente são privatizados e/ou ofertados em sistema de parcerias entre o setor público e privado. Essa estratégia é utilizada notadamente na área da educação, ferindo o princípio constitucional da gratuidade de ensino. Partindo destes pressupostos, o texto tem os objetivos de (i) discutir sobre as principais teses neoliberais; (ii) expor sobre a constituição histórica do neoliberalismo e da Terceira Via no Brasil e (iii) discutir sobre suas implicações para as políticas educacionais, no contexto atual, tendo como foco o Programa "Uma Ponte para o Futuro" do governo Temer. O estudo, feito por meio de pesquisa bibliográfica e análise documental, conclui que as medidas atuais do governo federal para a educação pública contribuem para seu desmantelamento, ao mesmo tempo em que favorece o setor privado empresarial apresentado como modelo a ser seguido na educação pública.

Palavras-chave: Política da educação. Democratização da Educação. Educação em parceria.

\footnotetext{
${ }^{1}$ Doutora em Educação pela UNESP-Marília. Pós doutora em Educação pela Universidade Federal do Rio Grande do Sul. Docente da Universidade Estadual de Londrina, no curso de Pedagogia e no Programa de pós-graduação em Educação. Líder do Grupo de Pesquisa Estado, Políticas Públicas e Gestão da Educação. E-mail: mjfruiz@gmail.com

2 Mestranda em Educação pela Universidade Estadual de Londrina. Membro do Grupo de Pesquisa Estado, Políticas Públicas e Gestão da Educação. Pedagoga na Rede Estadual de Ensino do Estado do Paraná.
} 
Ruiz e Bufalo

\section{UMA PONTE PARA O FUTURO: EDUCATIONAL POLICIES AND PUBLIC-} PRIVATE PARTNERSHIPS

Abstract: The text argues that neo-liberal and Third Way theses are not democratic, although they use the discourse of democracy to undertake their actions and gain social legitimacy. Although they present themselves as guardians of democracy, they are contrary to the initiatives of redistribution of wealth and the possibility of the working class's access to economic and social goods, through public policies subsidized by a provider State. Thus, currently much of the social rights conquered historically are privatized and/or offered in a system of partnerships between the public and private sector. This strategy is used notably in education, undermining the constitutional principle of free teaching. Based on these assumptions, the text aims to (i) discuss the main neoliberal theses; (ii) explain the historical constitution of neoliberalism and Third Way in Brazil, and (iii) discuss its implications for educational policies in the current context, focusing on Temer's government and its Program "Uma Ponte para o Futuro". The study, carried out through bibliographical research and documentary analysis, concludes that the current measures of the federal government for public education contribute to its dismantling while at the same time favor the private business sector presented as a model to be followed in public education.

Keywords: Educational politics. Democratization of Education. Partnership education

\section{UMA PONTE PARA O FUTURO: LAS POLÍTICAS EDUCATIVAS Y LAS ASOCIACIONES PÚBLICO-PRIVADAS}

Resumen: El texto defiende que las tesis neoliberales y de Tercera Vía no son democráticas, aunque utilicen el discurso de la democracia para emprender sus acciones y ganar legitimidad social. A pesar de presentarse como guardián de la democracia, son contrarias a las iniciativas de redistribución de riquezas y de posibilidad de acceso de la clase trabajadora a los bienes económicos y sociales, por medio de políticas públicas subsidiadas por un Estado proveedor. De esta forma, actualmente muchos de los derechos sociales conquistados históricamente son privatizados y/o ofrecidos en sistema de alianzas entre los sectores público y privado. Esta estrategia se utiliza notablemente en el ámbito de la educación, infringiendo el principio constitucional de la gratuidad de enseñanza. A partir de estos presupuestos, el texto tiene los objetivos de (i) discutir sobre las principales teses neoliberales; (ii) exponer sobre la constitución histórica del neoliberalismo y de la Tercera Vía en Brasil y (iii) discutir sobre sus implicaciones para las políticas educativas, en el contexto actual, teniendo como foco el Programa "Uma Ponte para o Futuro" del gobierno Temer. El estudio, realizado por medio de investigación bibliográfica y análisis documental, concluye que las medidas actuales del gobierno federal para la educación pública contribuyen a su desmantelamiento, al mismo tiempo que favorece al sector privado empresarial presentado como modelo a seguir en la educación pública.

Palabras clave: politicas educativas. la democratización de la educación. asociaciones público-privadas. 


\section{Introdução}

No contexto atual, as concepções conservadoras ganham força e se faz necessário retomar a velha discussão sobre o liberalismo, sua passagem para o neoliberalismo de Terceira Via, no sentido de ilustrar como estas teses são reeditadas e afetam a igualdade de direitos, bandeira de luta social constante. Tendo isso em vista, o texto tem três objetivos, a saber: (i) discutir sobre as principais teses neoliberais, (ii) expor sobre a constituição histórica do neoliberalismo e da Terceira Via no Brasil e (iii) discutir sobre suas implicações para as políticas educacionais, no contexto atual, tendo como foco o programa "Uma ponte para o futuro" do governo Temer.

O estudo, feito por meio de pesquisa bibliográfica e análise documental, aborda a educação como política pública que é a materialização da intervenção do Estado (sociedade política) e elaborada em articulação com a sociedade civil, em um jogo de forças políticas. A sociedade civil é constituída por instituições públicas e privadas que se articulam e tensionam seus interesses permanentemente. Por meio das lutas e das relações sociais, políticas e econômicas, os sujeitos sociais de grupos diversos, se articulam, no sentido de tornar seus interesses hegemônicos. Isso implica em considerar os interesses dos representantes do capitalismo e as forças contrárias que se condensam e ocupam o poder do Estado, neste período particular pelo qual passa a sociedade brasileira.

A partir destes pressupostos o texto organiza-se em cinco seções. A primeira discute a concepção de Estado. A seguir apresenta uma revisão das principais teses neoliberais das Escolas de Chicago, de Virginia e Austríaca, para delinear as similitudes com as politicas para a educação, na atualidade. Na seção seguinte discute os preceitos da Terceira Via, considerada como uma reedição do neoliberalismo, uma vez que continua a propalar o Estado mínimo para o social, porém, de forma camuflada. A quarta seção apresenta o percurso histórico e político do neoliberalismo e da Terceira Via, no caso brasileiro. Na última seção o texto traz uma análise do Programa "Uma Ponte para o Futuro", do Presidente Temer, evidenciando como este programa reedita as teses neoliberais, propondo o 
ajuste fiscal, a desvinculação de recursos, a desindexação de salários e reafirmando o compromisso com o setor empresarial e com as parcerias públicoprivadas.

\section{A questão do Estado}

Assim como Poulantzas (1977), considera-se que o Estado é produto da luta de classes. O Estado burguês, por se constituir no movimento desta luta, configura-se não como um Estado burguês, mas sim, por uma instituição que é dominada pela burguesia. Desta forma, os interesses da classe trabalhadora, também ali são tensionados, "isto apenas significa, [...], que o Estado não é utensílio de classe", mas sim, "que ele é o Estado de uma sociedade dividida em classes" (POULANTZAS, 1977, p. 186).

O Estado está em relação direta com a expansão global do capitalismo, sendo este considerado por Wood (2014), como o "coração do novo sistema global". É ele que cria as condições indispensáveis de acumulação de capital e atua como "garantidor administrativo e coercitivo de ordem social", salvaguardando as relações de propriedade e instituindo as condições básicas que são exigidas pelo capitalismo em sua vida cotidiana (WOOD, 2014, p. 106).

O movimento histórico deste sistema leva ao acirramento da cisão entre desenvolvimento econômico e desenvolvimento social (WOOD, 2006). Dizendo de outra forma, o capitalismo torna possivel que o desenvolvimento econômico dos países aconteça, sem que haja o desenvolvimento social, pelo menos, não na mesma proporção que o primeiro. Importante observar que as crises que ocorrem no sistema capitalista, não são apenas locais, mas, se alastram pelos países capitalistas cada qual com suas especificidades.

Desta forma, há a tentativa recorrente de superar a crise num processo de reestruturação do sistema jurídico, político e ideológico, que traz novos contornos para as instituições sociais. Essas reformas ocorrem de forma diferente em diferentes Estados Nacionais. Grosso modo, as estratégias seguem no sentido de gerenciar a crise, recuperando a estabilidade monetária, redefinindo o papel do Estado, para o qual é indicado que invista o mínimo possivel na área social (corte de gastos com serviços públicos). Nesta perspectiva, o Estado deve manter a capacidade de interferir na economia para salvar o mercado, quando assim for 
necessário e ainda atuar como um Estado avaliador, por meio de avaliações em larga escala.

Neste contexto, o país vivencia a luta pela democratização da educação pública, que, conforme Saviani (2014), ainda não aconteceu de forma plena e, considerando as propostas políticas atuais para a educação do Programa "Uma Ponte para o Futuro", corre o risco de não vir a acontecer, pelo menos não por estes tempos.

O neoliberalismo e a Terceira Via trazem consequências danosas para a questão social e provocam todo tipo de exclusão. Contribuem ainda para o entendimento de que o mercado é o modelo fundamental de regulação na área educacional. Tendo isso em vista, apresenta-se a seguir alguns elementos teóricos, de autores neoliberais que continuam influenciando, de forma implícita ou explícita, as políticas para a educação em nível mundial, sendo estes: Hayek (1990), Buchanan (1999), Schultz (1967) e Friedman (1984).

\section{Revisitando conceitos neoliberais para entender o contexto atual}

Os teóricos neoliberais se organizam no sentido de refutar as teses desenvolvidas por Keynes (1883-1946), grande influenciador da politica econômica do século XIX nos países ocidentais. Keynes propunha uma intervenção maior do Estado, com o objetivo de controlar as forças econômicas e preservar os direitos sociais (previdência, educação, saúde). A crise econômica do capital, no início do século XX, é tratada como uma crise política, o que passa a justificar a proposição da limitação da intervenção do Estado.

Hayek (1990), ao analisar a crise do pós-guerra na Europa, escreve o livro "O caminho da servidão", no qual, grosso modo, propõe a mínima intervenção do Estado, a privatização e uma maior rigidez com os sindicatos e movimentos sociais, pois, em sua análise, por conta das constantes reinvindicações destes grupos, o Estado acaba se endividando além de suas possibilidades. Seu alvo principal, naquele momento, era o Partido Trabalhista inglês, que tinha uma proposta embasada na socialdemocracia. Contudo, é com a crise de 1973, quando o capitalismo cai novamente em recessão, que o ideário neoliberal se fortalece e ganha terreno (ANDERSON, 1995). 
Para Hayek (1990), a democracia é um problema, uma vez que para atender as demandas dos eleitores, o legislativo estabelece políticas sociais de redistribuição de renda, que atrapalham o livre desenvolvimento do mercado, pois, desestabilizam o ciclo natural da economia e provocam a crise fiscal. A democracia, assim, seria uma forma totalitária de governo. Nesta perspectiva, é o Estado que provoca a crise financeira do capitalismo. A saída da crise, portanto, segue no sentido de modernizar o Estado. Cabe, por conseguinte, ao mercado suprir as falhas do Estado, uma vez que sua lógica operacional é mais eficiente e produtiva.

Além da Escola Austríaca, outras escolas influenciam, histórica e internacionalmente, a teoria neoliberal, cada qual com sua especificidade, a saber:

[...] a Escola de Virginia Public Choice, que tem em Buchanan seu principal representante, e desenvolve o conceito de quase-mercado, que é a proximidade das orientações públicas às orientações de mercado; e a Escola de Chicago, com Friedman e a Teoria do Capital Humano de Theodore Schultz (PERONI, 2013, p. 237).

A teoria da escolha pública (Public Choice) emprega o método econômico para resolver os problemas políticos. Este método centra-se no indivíduo, entendendo que somente ele é sujeito das ações individuais ou coletivas. É o indivíduo que tem interesses, preferências, valores e motivações. Partindo desta premissa, a Public Choice defende que os grupos e as organizações públicas ou privadas, são um conjunto de indivíduos. Não se observa, assim, uma concepção orgânica acima desses indivíduos.

Dessa forma, Buchanan (1999) vê inconsistência na concepção que afirma que os indivíduos no mercado são egoístas, mas, quando estes atuam na política, se tornem altruístas e defendam ali o interesse público. Assim, propõe a abordagem da política sem romances e desenvolve a concepção de que o setor público opera de forma muito próxima às orientações do mercado, são assim, espaços de quase-mercado.

A Escola de Chicago, por sua vez, tem como um dos expoentes Friedman e a Teoria do Capital Humano de Schultz, embora estas perspectivas teóricas tenham diferenças, conforme tratamos a seguir. Para Schultz (1967), a educação 
tem valor econômico e, sendo assim, as escolas podem ser consideradas empresas que têm como finalidade produzir a instrução. Embora considere que a instituição educacional, não tenha as mesmas características de uma indústria convencional, uma vez que não busca a obtenção do lucro imediato, entende que a instrução elevará a renda dos estudantes no futuro, então pode ser vista como um investimento. $\mathrm{O}$ autor entende também que a educação tem uma perspectiva multidimensional e serve assim a fins sociais, politicos e outros. Contudo, Schultz (1967) não exclui a aplicação da análise econômica para a educação, uma vez que investimento em educação será retornado em crescimento da economia.

Friedman $^{3}$ (1984), por sua vez, aborda a questão do capitalismo competitivo, defendendo que a empresa privada precisa ter liberdade econômica e liberdade politica. Critica as teses socialistas, entendendo que restringem a liberdade individual e, portanto, não são democráticas. Faz críticas à ação do governo na oferta gratuita da educação pública, considerando esta questão um alargamento indiscriminado de sua responsabilidade.

Ao discorrer sobre o papel do governo na educação, interpreta a questão da educação pública de dois modos negativos. A princípio, a educação pública impõe um custo para todos os indivíduos e estes não têm como forçar a compensação deste investimento, assim o investimento não é voluntário. Em segundo plano porque entende a educação pública como um "interesse paternalista pelas crianças e por outros indivíduos irresponsáveis” (FRIEDMAN, 1984, p. 17).

Assim, propõe um mínimo possível de educação geral aos cidadãos, necessária para o desenvolvimento de uma sociedade democrática, regulada pelo livre mercado, uma vez que o mercado precisa de uma base elementar de conhecimentos para fazer fluir a produção de mercadorias. Friedman (1984) formula proposições para a educação primária, secundária e superior, nos Estados Unidos que, aparentemente, tem servido de subsídio para as politicas educativas em diferentes regiões da América Latina e do Brasil. Para a educação

${ }^{3}$ Conforme Ravitch (2011) Ronald Reagan embasou grande parte da reforma da Educação dos EUA no ideário neoliberal de Milton Friedman. Embora tenha havido resistência, a perspectiva da escolha escolar (bônus públicos, destinados às escolas escolhidas pelos pais) foi sendo fortalecida nas políticas para a educação deste país e contribuiu para o crescente desmonte do sistema escolar público americano. 
primária e secundária, o autor defende que o recurso público possa ser utilizado apenas em casos justificados em que a família não possa arcar com a educação de seus filhos.

Já a educação superior não deveria ser ofertada pelo Estado, em uma sociedade livre. Considera a concorrência entre as universidades públicas e privadas, nos Estados Unidos ${ }^{4}$, muito injusta uma vez que, as públicas cobram mensalidades mais baixas, colocando o sistema privado em condições desiguais. Assim, indica que

Qualquer subvenção deve ser passada aos indivíduos, para ser utilizadas em instituições de sua própria escolha, com a única condição de que sejam do tipo e natureza convenientes. As escolas governamentais que continuarem em funcionamento deveriam cobrar anuidades que cobrissem os custos educacionais, competindo, assim em nível de igualdade com as escolas não subvencionadas pelo governo (FRIEDMAN, 1984, p. 94).

A nacionalização das escolas custeadas pelo governo afeta as empresas privadas que atuam na área da educação. Propõe assim que o governo possa exigir um nível mínimo de instrução financiada. Isso seria possivel se for estipulado um valor máximo anual por filho, que adicionado aos recursos próprios, deveria ser usado pelos pais na compra de serviços educacionais. Com este recurso, os serviços educacionais poderiam ser adquiridos em empresas privadas, com fins lucrativos, que seriam as fornecedoras, ou, também por instituições sem finalidade educativa. Defende então políticas de aplicação de bônus do governo a serem utilizados pelos pais na escolha da escola para seus filhos, isso contribuiria para um processo contínuo de desnacionalização e privatização das escolas, o que para ele, é necessário para a ampliação do livre mercado e das liberdades individuais.

Friedman (1984) considera um erro que os governos invistam em capital humano, pois, não há nenhuma forma de regular o retorno deste investimento, o que é diferente quando se investe em capital físico, que pode ter seu retorno garantido por meio de recursos jurídicos, a exemplo das hipotecas. Para ele,

\footnotetext{
${ }^{4}$ Este ideário é muito presente entre a classe empresarial brasileira para a educação e expresso em revistas que
} veiculam seus interesses, a exemplo da revista Veja. 
mesmo se a sociedade fosse escravocrata, mesmo assim, o retorno da instrução para o mercado produtivo não seria certo. Portanto,

[...] esse subinvestimento no capital humano reflete provavelmente uma imperfeição do mercado de capital. [...] Um empréstimo para financiar o treinamento de um indivíduo que não tem nada a oferecer a não ser seus ganhos futuros, é, portanto bem menos atrativo do que um empréstimo para financiar a construção de um prédio - a garantia é menor, e o custo do recolhimento dos juros e do principal é bem maior (FRIEDMAN, 1984, p. 96).

Desta forma, observa-se que as Escola Austríaca, como a Escola de Virginia, como a Escola de Chicago não tratam a educação como possibilidade de formação humana plena e como possibilidade de elaboração da cultura e do conhecimento científico, que vise formar "pessoas humanas" melhores. Por outro lado, as três escolas enaltecem a função unidirecional da educação como mola propulsora para a ascensão da economia de mercado.

Isso tem concorrido para o processo de mercadificação da educação, que, aparentemente, ganha força em periodo que o Brasil passa por forte retorno ao conservadorismo. O fenômeno da mercadificação de tudo, conforme Harvey (1996), acirra ainda mais a desigualdade social. Isso ocorre porque aquilo que é direito (neste caso a educação) e, portanto, pede a elaboração de políticas sociais que garantam aos sujeitos sociais terem acesso a eles, sede lugar para práticas individualistas e meritocráticas. A educação é vista como mercadoria e os sujeitos como consumidores, afastando-se assim da perspectiva de educação pública universal, de gestão pública, que atenda de forma indistinta todos os sujeitos sociais. Neste sentido, concordamos com Ravitch (2011, p. 254) quando afirma que:

Nossas escolas não vão melhorar se nós esperarmos que elas ajam como empresas privadas buscando o lucro. Escolas não são negócios; elas são um bem público. O objetivo da educação não é produzir maiores escores, mas sim, educar as crianças para que elas se tornem pessoas responsáveis com mentes bem desenvolvidas e um bom caráter.

No entanto, de forma geral, para além da educação, historicamente o neoliberalismo tem contribuído para que o capital possa cada vez mais se acumular nas mãos de poucos indivíduos, ou de pequenos grupos. Esses grupos, 
por meio de suas redes, têm conseguido formar consensos em diferentes áreas da sociedade e têm influenciado a condução das políticas públicas, solapando, uma série de leis protetivas aos trabalhadores, conquistadas por meio de lutas históricas.

\section{A Terceira Via e a reedição das teses neoliberais}

Na década de 1990 ganham força também as teses de Giddens (2001) que, segundo o autor, são elaboradas na tentativa de transcender o neoliberalismo, e também a "social democracia do velho estilo" (GIDDENS, 2001, p. 36). Para ele, os neoliberais defendem a redução do tamanho do Estado e a social democracia persiste no entendimento que é necessário expandi-lo. A proposta da Terceira Via segue na direção de nem reduzir, nem expandir, mas, sim, reformar o Estado.

A discussão sobre a Terceira Via ganha força como discurso ideopolitico quando Tony Blair, líder do Partido Trabalhista britânico, redefine a proposta da social-democracia 5 , na tentativa de superar o neoliberalismo de Tatcher. Dessa forma, estabelece propostas que se voltam para a abertura politica, para a desregulação e para a desestatização da economia nacional. Este novo formato dado para a social-democracia resulta na perspectiva da Terceira Via considerada como uma tentativa de defender uma política econômica conservadora, que se alie a uma politica social progressista, superando, ao mesmo tempo, a velha socialdemocracia de Keynes e o neoliberalismo ortodoxo de Thatcher (GROPPO; MARTINS, 2008).

Giddens (2001) foi o teórico que formatou a proposta ideológica e politica da Terceira Via, dando apoio para Blair e cuja referência teórica passa a amparar a proposta politica de diferentes governos nacionais. Contudo, conforme Martins (2009, p. 60), a Terceira Via se realinha ao projeto neoliberal e insere a participação da sociedade que passa atuar como articuladora de uma nova sociabilidade, que visa consolidar um modelo de capitalismo humanizado, que não conduza a resistências e "abalos na coesão social dos diferentes países”.

5 A social-democracia origina-se de uma ruptura dentro os defensores do socialismo e passa a defender a transição para o socialismo sem a necessidade de uma revolução, ou seja, por meio de reformas. No entanto, em seu desdobramento histórico se aproximou mais da perspectiva conservadora da direita do que da esquerda (progressista). 
Tanto para a Terceira Via, como para o neoliberalismo, o culpado pela crise econômica é o Estado. Contudo, as possibilidades de superação são diferenciadas entre estas duas vertentes teóricas. Para os neoliberais, a saída é a privatização, para a Terceira Via a saída é o terceiro setor (PERONI, 2013). Este último composto por atores individuais e associações voluntárias do tipo Organizações Não-Governamentais (ONGs), cujas atribuições incluiriam a parceria com o Estado na execução de políticas sociais, em especial na área da assistência social e da educação (GROPPO; MARTINS, 2008), tendo uma conotação bastante ideológica (MONTAÑO, 2002).

Importante esclarecer que sociedade civil e terceiro setor são conceitos bastante ambíguos e têm sido utilizados de forma ideológica pelos defensores da Terceira Via. O terceiro setor, para Montaño (2002), é uma construção abstrata e ideológica, a fim de mascarar os conflitos sociais. Para este autor tal construção ideológica pauta-se na existência do primeiro setor (Estado), do segundo setor (mercado) e terceiro setor (entidades organizadas na sociedade civil). Essa fragmentação tem contribuído para que o Estado se afaste legalmente de sua responsabilidade de mantenedor dos direitos sociais, transferindo-os para entidades assistencialistas e filantrópicas.

Por sua vez, o conceito de sociedade civil aparece na construção discursiva do grupo empresarial, de forma abstrata sem considerar a questão das classes sociais distintas. Este grupo para ter legitimidade, como qualquer representante do capital, se apresenta como se todos os seus interesses estivessem voltados para o bem comum. Assim, o conceito de sociedade civil pode abranger grupos que lutam para ter acesso aos mais básicos dos direitos sociais, a exemplo do movimento de sem tetos, como também pode abarcar todo tipo de movimento empresarial (WOOD, 2006).

Contudo, o curso da história mostra que o empresariado tende a operar a fim de obter a maior lucratividade possivel, depredando o meio ambiente e submetendo o trabalho humano a diferentes formas de precarização (baixos salários, jornadas de trabalho extenuantes, insalubridade, inobservância dos direitos trabalhistas). Agindo assim, o movimento empresarial passa longe do bem comum e inclina-se a buscar interesses privados e particulares, tendo em vista o maior acúmulo de capital possível, procurando novos mecanismos de acumulação 
de capital no mercado financeiro, movimento que Harvey (2010) nomina de acumulação por espoliação.

Wood (2006, p. 209) reitera essa ideia ao mostrar que a "sociedade civil abrange uma série de instituições e relações, de lares, sindicatos, ações voluntárias [...] até o mercado, empresas capitalistas, enfim toda a economia capitalista. Assim, busca-se diluir ideologicamente todo e qualquer conflito entre as classes sociais. A sociedade civil torna-se um espaço para o qual desloca-se a iniciativa de resolução dos problemas de ordem social, o que tem sido usado para reduzir o investimento do Estado em políticas sociais.

Desta feita, o uso que a Terceira Via faz da concepção de sociedade civil vai contra ao sentido que Gramsci (1979) atribuía a ela, pois, para Gramsci, conforme aponta Wood (2006, p. 208), o “conceito de 'sociedade civil' deveria ser, sem ambiguidades, uma arma contra o capitalismo, nunca uma acomodação a ele". Concorda-se com Wood (2006), ao entender que a cooptação do conceito pela Terceira Via tem enfraquecido a resistência às coerções do capitalismo.

Para Giddens (2001), é importante que o Estado valorize e apoie as ações da sociedade civil, por meio dos investimentos que forem necessários, mas que não se envolva diretamente em seus projetos. Exalta-se assim as iniciativas de solidariedade, de trabalho voluntário e outras medidas que podem ampliar a inclusão social. Com esta proposta, a Terceira Via reforça a perspectiva da parceria público-privada na execução das politicas sociais. Assim, propõe "uma nova sinergia entre os setores público e privado, utilizando o dinamismo dos mercados, mas tendo em mente o interesse público" (GIDDENS, 2001, p. 109).

Isso posto, tanto o neoliberalismo como a Terceira Via têm o mercado como parâmetro de qualidade, sendo esta a fórmula utilizada para mensurar a oferta dos serviços sociais. Entende-se que a Terceira Via ataca as teses neoliberais, para preservá-las, uma vez que preserva as relações de poder estabelecidas no capitalismo, redefine a natureza das politicas sociais e coloca em destaque o protagonismo da sociedade civil.

Assim, a sociedade civil passa a ser a nova roupagem para o empresariado que institui associações e organizações de toda ordem, que ofertam medidas de proteção social, por meio do voluntariado e da benevolência, com interesses nada fácil de identificar. Isso tem contribuído para aprimorar cada vez mais a 
sociabilidade do capital e estabelecer uma conformidade capaz de assegurar a coesão social em torno de um projeto que visa compatibilizar a perversa economia de mercado, com a justiça social e ainda mais contribui para educar a sociedade no entendimento de que não há mais luta de classes e sim relações de solidariedade entre as classes.

\section{As reformas neoliberais de Terceira Via no Brasil}

A reforma do Estado no Brasil seguiu na esteira das reformas já realizadas anteriormente em países a exemplo dos Estados Unidos e Inglaterra, com Reagan, Thatcher, respectivamente. Assim como, tendo em vista a modernização conservadora proposta pelo novo trabalhismo de Blair, embora adaptando estas medidas as especificidades nacionais, o que resulta em processos diferentes, haja vista a própria história do país que, em meados da década de 1980, acabava de sair de um período longínquo de vinte anos de governos ditatorial.

Dito de outra forma, os países centrais já vinham de uma tradição democrática mais estável de luta e de jogo de forças sociais e políticas, no sentido de tentar conquistar direitos, enquanto no Brasil, quando o neoliberalismo e a Terceira Via se estabelecem, este movimento de conquista pelos direitos mal estava se iniciando, quando é solapado por esta onda de modernidade conservadora. Neste período de reformas, o Brasil é impactado pelas políticas da Terceira Via quase em tempo real, tendo em vista a novas tecnologias de informação e comunicação, que possibilitaram o acompanhamento daquilo que acontecia no contexto europeu e norte-americano (GROPPO; MARTINS, 2008).

Neste país, o neoliberalismo foi o marco das reformas em diferentes áreas, principalmente no governo de Fernando Collor de Melo (1990-1992). Em 1995, quando Fernando Henrique Cardoso (FHC -1995-2002) assumiu a presidência da república, deu sequência às políticas neoliberais dos governos anteriores e uma de suas ações foi instituir o Ministério da Administração e Reforma do Estado (MARE), empossando Luiz Carlos Bresser Pereira como Ministro responsável. Seguiu-se daí a elaboração de uma proposta para redefinir as ações do Estado brasileiro, organizada em vários cadernos, sendo um deles nominado de Plano Diretor da Reforma do Aparelho do Estado (BRESSER PEREIRA, 1995). 
Segundo Groppo e Martins (2008), "Bresser Pereira havia feito um 'estágio" na Inglaterra, voltando de lá disposto a promover a aplicação dos princípios da Terceira Via na reforma do Estado brasileiro", no sentido de torná-lo gerencial, uma vez que até então, segundo o ministro, o Estado brasileiro era patrimonial. Assim,

Nas palavras de Paoli (2002), enquanto que na Inglaterra o discurso da Terceira Via, bem ou mal, era um contraponto ao radicalismo antiestatista do neoliberalismo de Margareth Thatcher, no Brasil, este fez verdadeiro papel de combate aos direitos sociais e instituições estatais que apontavam, desde o fim do Regime Militar, para uma espécie de Estado de Bem-Estar "fora de época" - ainda que de modo algum "fora de propósito" em uma sociedade com extrema desigualdade e dividas sociais imensas (GROPPO; MARTINS, p. 2008 - grifos do autor).

Dessa forma, Groppo e Martins (2008) demonstram como, desconsiderando as questões históricas, políticas e econômicas do Brasil, na década de 1990, Giddens (2001) e Bresser Pereira defendem que havia possibilidade da perspectiva da Terceira Via vir a promover ascensão da economia, tanto na Inglaterra, assim como no Brasil, o que seria, conforme Bresser Pereira (1995), um salto diretamente para o Estado gerencial.

O diagnóstico dos reformadores parte da constatação de que o Estado é uma máquina burocrática que prejudica o desenvolvimento da economia de mercado. Desloca-se assim, intencionalmente, a causa da crise econômica para a instituição estatal. A partir do diagnóstico do Plano Diretor, algumas indicações foram feitas para amenizar a crise financeira. Dentre elas, a passagem de alguns serviços públicos essenciais, garantidos pela Constituição Federal de 1988, para instituições não estatais. Dentre estes serviços, a educação, a saúde e outros. Estas áreas são vistas como lucrativas e, portanto, podem ser exploradas por diferentes setores da economia. A partir dos três eixos da reforma, privatização, publicização e terceirização iniciou-se a proposição de uma série de hibridismos que redefinem a fronteira entre o setor público e privado (PERONI, 2013).

Silva (2003, p. 105) aponta que com a redefinição do Estado difundiu-se uma construção no plano ideológico, que contribuiu para mascarar "a expansão do capital em áreas antes consideradas essencialmente públicas, colocando em xeque o caráter universalista de serviços como saúde e educação". Estimula-se, 
assim, a transferência da prestação de serviços, antes sob a responsabilidade do Estado, para o terceiro-setor. Por meio das parcerias, o Estado vai se eximindo de ser investidor de recursos para as áreas sociais, mas permanece centralizando as ações de fiscalizador e avaliador destes serviços.

Neste contexto de alargamento das forças neoliberais, o final do século XX, no Brasil, foi marcado por uma crescente ambiguidade. Por um lado, houve o crescente descontentamento dos movimentos populares, sindicais, dentre outros, tendo em vista a desregulamentação ou a precarização das políticas sociais conquistadas e expressas na $\mathrm{CF} / 88$. Por outro lado, alguns setores do empresariado mercantil começaram a rever suas disposições em apoiar as reformas orientadas pelo governo. Esse movimento estabeleceu as condições para o adensamento de forças politicas que envolveram tanto os setores da classe dominante, assim como setores da classe dominada.

De tal modo, nos primeiros anos deste século, o projeto social-democrático foi reeditado nos moldes do neodesenvolvimentismo 6 proposto pelo Partido dos Trabalhadores (PT) 7 . Para Alves (2014), o neodesenvolvimentismo se desenvolve a partir "da crise da ortodoxia neoliberal", e, portanto, não poderia se tratar de simples continuidade ao projeto neoliberal, ocorrido na década de 1990. O neodesenvolvimentismo foi proposto como um "projeto burguês alternativo à lógica destrutiva das politicas neoliberais" (ALVES, 2014, p.135), uma vez que, já na segunda metade da década de 1990, setores da grande burguesia brasileira, que apoiavam as politicas do governo, já mostravam descontentamento com estas políticas.

Assim, a eleição do Partido dos Trabalhadores, no ano de 2003, vem no sentido de propor a construção de um novo padrão de desenvolvimento para o sistema capitalista. Em seu primeiro governo (2003-2006), o PT já deixou explícito que sua proposta de governo neodesenvolvimentista não seria anticapitalista,

${ }^{6} \mathrm{O}$ neodesenvolvimentismo é um programa político, econômica e social que visa o desenvolvimento econômico do capitalismo brasileiro, com algumas medidas paliativas de transferência de renda, contudo sem extrapolar os limites impostos pelo modelo econômico neoliberal.

${ }^{7}$ O PT permaneceu no poder nas gestões de Luís Inácio Lula da Silva (2003-2010) e Dilma Roussef (20112014). A Presidente Dilma passou por um processo de impedimento, no ano de 2016. 
mas, ao contrário disso, se manteria alinhada ao neoliberalismo, proposta hegemônica no mercado mundial (ALVES, 2014).

Antes mesmo de ser eleito, ainda em campanha politica, no ano de 2002, Lula encaminhou para edição a "Carta aos Brasileiros" na qual se comprometia a respeitar os contratos e, principalmente, o pagamento dos credores da divida pública. Assim podemos entender, concordando com Alves (2014, p. 135) que

[...] o projeto político do lulismo alternativo à ortodoxia neoliberal, era o neodesenvolvimentismo, afirmação periférica do reformismo social-democrata, que atribuía à parceria do estado com o mercado o papel de indutor da economia capitalista no Brasil [...].

A perspectiva neodesenvolvimentista se materializou, por exemplo, no Plano de Aceleração do Crescimento (PAC) que propôs a rápida indução do crescimento da economia do país, tendo como um de seus eixos as Parecerias Públicoprivadas (PPP). Segundo Peroni (2013, p. 246), há que se destacar que, se FHC participava dos encontros "da Governança Progressista, como era chamada a Terceira Via desde o seu início em 1999, em Florença”, Lula deu continuidade a esta participação.

Isso posto, é possivel entender que o governo do PT, também no que se refere à gestão da Presidente Dilma, continuou conivente com a perspectiva da Terceira Via, ou ao menos, mostrou-se aliado a ela. Este governo reforçou o principio das parcerias, da publicização, das terceirizações, dando continuidade a muitas destas propostas.

\section{Politicas para a democratização da educação: do PDE de Lula à Ponte para o futuro de Temer}

Conforme Saviani (2007), a ascensão do PT ao governo federal, instigou ainda mais a articulação do poder público com o empresariado. Isso afastou o partido de suas bases originárias. Em 2007, quando formulou o Plano de Desenvolvimento da Educação (PDE), buscou interlocução com o empresariado e desconsiderou as proposições dos movimentos dos educadores, muitas delas expressas no Plano Nacional de Educação (PNE - 2001-2010). Inclusive escolheu 
assumir a agenda empresarial do Movimento Compromisso Todos pela Educação ${ }^{8}$.

Importante destacar que a agenda do empresariado para a educação contrasta com a defesa da escola pública, universal e gratuita. Assim, para Frigotto (2011), a adesão empresarial ao PDE explicitou "o caráter cínico do movimento e a disputa ativa pela hegemonia do pensamento educacional mercantil no seio das escolas". Este mesmo autor, ao realizar um balanço da educação no Brasil, na primeira década do século XXI, reflete sobre as permanências, continuidades e descontinuidades das ações neoliberais expressas nas políticas educacionais, neste período, e alerta que

No plano das políticas educacionais, da educação básica à pós graduação, resulta, paradoxalmente, que as concepções e práticas educacionais vigentes na década de 1990 definem dominantemente a primeira década do século XXI, afirmando as parcerias do público e privado, ampliando a dualidade estrutural da educação e penetrando, de forma ampla, mormente nas instituições educativas públicas, mas não só, e na educação básica, abrangendo desde o conteúdo do conhecimento até os métodos de sua produção ou socialização (FRIGOTTO, 2011, p. 242).

Do exposto, entende-se que o movimento histórico acerca das políticas educacionais desenvolvidas no Brasil revela que elas estão sendo organizadas em órbita do movimento internacional do capital, todavia, vivenciam-se os reflexos das crises intrínsecas do capitalismo, do modo mais perverso e inimaginável, dada a profundidade da desigualdade econômica e social em que a sociedade está inserida.

Com o impedimento da Presidente Dilma, o PT deixa de ocupar o poder do Estado. Temer assume interinamente a Presidência da República, em um processo bastante conflituoso. Nesta conjuntura, logo no início de seu governo, divulga o Programa "Uma Ponte para o Futuro" (FUNDAÇÃO ULYSSES GUIMARÃES, 2015), vinculado ao PMDB (Partido do Movimento Democrático Brasileiro).

8 “Movimento lançado em 6 de setembro de 2006 no Museu do Ipiranga, em São Paulo. Apresentando-se como uma iniciativa da sociedade civil e conclamando a participação de todos os setores sociais, esse movimento se constituiu, de fato, como um aglomerado de grupos empresariais (SAVIANI, 2007, p. 1243). 
O referido documento foi apresentado como um programa de governo destinado a preservar a economia brasileira e tornar viável o seu desenvolvimento, acabando com a vinculação de recursos constitucionais, desindexando salários e reforçando as parcerias entre o setor público e o setor privado. Dentre as propostas apresentadas, a primeira medida foi acionar o Congresso Nacional para aprovação de algumas medidas, dentre elas, a prioridade em

Acabar com as vinculações constitucionais estabelecidas, como no caso dos gastos com a saúde e com a educação [...]. Para um novo regime fiscal, voltado para o crescimento, e não para o impasse e a estagnação, precisamos de um novo regime orçamentário, com o fim de todas essas vinculações e a implantação do orçamento inteiramente impositivo (FUNDAÇÃO ULYSSES GUIMARÃES, 2015, p. 9).

A citação acima tem o intuito de destacar a temática da desvinculação de recursos para a educação, a título de ilustrar a concepção neoliberal de minimização do papel do Estado nas proposições e implementações das políticas públicas no Brasil. Segue-se ainda outro fragmento do mesmo documento, no intuito, de compor o exemplo clássico das ações de defesa do mercado em detrimento das ações sociais.

Como mostrou o Fórum Econômico Mundial, nosso ambiente de negócios não é favorável [...]. Recriar um ambiente econômico estimulante para o setor privado deve ser a orientação correta para a política de crescimento. Tudo isso supõe ação do Estado. [...] A globalização é o destino das economias que pretendem crescer. [...] Portanto é fundamental: estabelecer um limite para as despesas de custeio inferior ao crescimento do PIB, através de lei, após serem eliminadas as vinculações $\mathrm{e}$ as indexações que engessam $\mathrm{o}$ orçamento; executar uma politica de desenvolvimento centrada na iniciativa privada, por meio de transferências de ativos que se fizerem necessárias; permitir que as convenções coletivas prevaleçam sobre as normas legais (FUNDAÇÃO ULYSSES GUIMARÃES, 2015, p.15-19).

Estas afirmações encontradas no Programa em questão destacam seu caráter neoliberal, portanto, contrário ao ideário democrático, proposto como regime político desde 1988 no Brasil e expresso da Constituição Federal. Ao propor a desregulamentação de leis trabalhistas e favorecer as convenções 
coletivas, o governo fragiliza a relação de trabalho em todas as áreas, deixando o trabalhador exposto às diferentes formas de expropriação de seu trabalho (diminuição de salários, flexibilização de turno e carga horária, etc).

Sobre a desvinculação constitucional de recursos para a educação, Menezes (2008) identifica em seu estudo que em diferentes Constituições Federais, desde 1934 a 1988, ela tem sido utilizada em períodos ditatoriais, como em 1937, em que a ditadura do Estado Novo revogou a vinculação de recursos financeiros para a área:

O delineamento temporal [...] evidencia que a vinculação se apresentou de forma intercalada nas Cartas Constitucionais, tendo sido revogada na Constituição da ditadura do Estado Novo (decretada em 1937) e na Carta de 1967, que sucedeu o golpe militar de 1964. Afora os momentos de descontinuidade, a vinculação assumiu percentuais crescentes, apresentando seu maior valor quando da promulgação da atual Carta Constitucional, em 05 de outubro de 1988 (MENEZES, 2008, p.154).

A partir do texto de Menezes pode-se constatar que a luta sobre a vinculação de recursos para a educação é inerente ao processo de luta pela real democratização do país. E ainda que em todo momento onde as forças conservadoras estão explicitamente no poder, a desvinculação é decretada.

Ao propor a desvinculação de recursos para a educação, esse Programa retira a garantia de igualdade de condições para todos, além disso, destaca o papel do Estado para estabelecer parcerias com o setor privado, reflete uma proposta de educação dualista, em que as pessoas da classe trabalhadora terão uma educação voltada para o mercado de trabalho, reduzindo a possibilidade de conhecimento e emancipação humana. Assim, opta por favorecer a iniciativa privada, inclusive destinando recursos públicos para ela, como destaca-se na citação a seguir.

O ideal seria garantir que cada trabalhador, ocupado ou não, o direito a uma formação anual. Esta oportunidade representada por um cupom, pode ser utilizada como um ativo para aqueles que procuram empregos [...]. Em 2011 o Governo Federal criou, no âmbito do Ministério da Educação, um programa nacional de acesso à formação técnica - Pronatec - uma iniciativa que unificou as diversas atividades de qualificação profissional que estavam dispersas por várias áreas do governo. [...] O principal braço operativo do programa são as entidades do Sistema $\mathrm{S}$ e o 
financiamento provém de recursos do orçamento fiscal da União. (FUNDAÇÃO ULYSSES GUIMARÃES, 2015, p. 10-11).

Entende-se que seja contraditório um programa de governo organizado como saída para uma crise econômica, sendo necessário cortar recursos da educação pública, ao mesmo tempo apresentar um sistema de parceria, no qual irá disponibilizar recursos para a iniciativa privada. Mas, esta ação é totalmente coerente com os preceitos do neoliberalismo e da Terceira Via. De acordo com Frigotto (2011), o mais chocante é que o Sistema S, em 2010, mobilizou aproximadamente 16 bilhões de recursos públicos, somando-se os recolhidos compulsoriamente pelo Estado e a ele repassados, e a venda de serviços ao setor público.

Leda Paulani (2008), sobre as consequências das políticas neoliberais em curso, que provocam a urgência de se buscar brechas para promover uma educação emancipadora, alerta que

[...] nenhum determinismo ideológico pode aventurar-se a prever o futuro, mas parece muito evidente que, se não enfrentarmos o apartheid social, afundaremos na barbárie que já nos assombra e pereceremos como nação (PAULANI, 2008, p.139).

O apartheid social está se oficializando a partir do Programa "Uma Ponte para o Futuro", um futuro de uma servidão financeira, extremamente excludente e desigual. Diante dessa conjuntura, qual o movimento possível? $O$ único percurso seria a travessia da ponte? Uma ponte com bifurcações bem definidas, onde os direitos não podem ser para todos? Talvez haja outro caminho com possibilidades de se ter um mundo mais humano, menos reificado, com condições dignas de vida para todos. Contudo, este caminho ainda está por ser construído.

\section{Considerações finais}

Buscar as respostas a certas indagações pelos "circuitos da história" (FRIGOTTO, 2011) possibilitou descobrir que o que parecia inusitado até então, como a proposta de desvinculação de recursos da educação, na Constituição Federal, não é matéria nova. Na luta pela real democratização da educação no Brasil, essa garantia tem oscilado tanto quanto o próprio movimento pela democratização política no país, entre avanços e recuos dessa história. 
A força do neoliberalismo e da Terceira Via como ferramentas teóricas de regulamentação do modo de produção pode ser constatada pelos balanços teóricos e históricos tratados neste texto. Todavia, o Programa "Uma ponte para o futuro", apesar de ser a continuidade de uma trajetória iniciada há várias décadas, infelizmente, é um percurso que aponta para um recuo nas conquistas históricas pela efetivação dos direitos sociais.

Resta saber se a força política e as mobilizações dos movimentos e organizações sociais progressistas vão fazer frente e alcançar êxito para barrar cenário tão nefasto que se delineia nestes tempos de barbárie social.

\section{Referências}

ALVES, G. Trabalho e neodesenvolvimentismo: choque de capitalismo e nova degradação do trabalho no Brasil. Bauru: Práxis, 2014.

ANDERSON, P. Balanço do Neoliberalismo. In: SADER, E.; GENTILI, P. Pósneoliberalismo: as politicas e o estado democrático. São Paulo: Paz e Terra, 1995.

BRESSER PEREIRA, L. C. Plano Diretor da Reforma do Aparelho do Estado no Brasil. Brasília, 1995.

BUCHANAN, J. M. The Logical Foundations of Constitutional. Indianapolis: Liberty, 1999.

FRIEDMAN, M. Capitalismo e Liberdade. São Paulo: Abril Cultural, 1984.

FRIGOTTO, G. Os circuitos da história e o balanço da educação no Brasil na primeira década do século XXI. Revista Brasileira de Educação, Rio de Janeiro, v.16, n. 46, p. 235-274, 2011.

FUNDAÇÃO ULYSSES GUIMARÃES. Uma ponte para o futuro. PMDB, 2015. Disponivel em: <http://pmdb.org.br/wp-content/uploads/2015/10/RELEASETEMER_A4-28.10.15-Online.pdf $>$. Acesso em: ago. 2016.

GIDDENS, A. A Terceira Via: reflexões sobre o impasse politico atual e o futuro da social-democracia. Rio de Janeiro: Record, 2001.

GRAMSCI, A. Os Intelectuais e a Organização da Cultura. 3 ed. Rio de Janeiro: Civilização Brasileira, 1979.

GROPPO, L. A.; MARTINS, M. F. Terceira Via e politicas educacionais: um novo mantra para a educação. Revista Brasileira de Politica e Administração da Educação, Goiânia, v. 24, n. 2, p. 215-233, 2008.

HARVEY, D. Condição pós-moderna: Uma pesquisa sobre as origens de mudança cultural. São Paulo: Loyola, 1996.

HARVEY, D. O novo imperialismo. 4. ed. São Paulo: Loyola, 2010. 
HAYEK, F. A. V. O caminho da servidão. Rio de Janeiro: Instituto Liberal, 1990.

MARTINS, A. S. A direita para o social: a educação da sociabilidade no Brasil contemporâneo. Juiz de Fora: UFJF, 2009.

MENEZES, J. S. da S. A vinculação constitucional de recursos para a educação: Os (des) caminhos do ordenamento constitucional. HISTEDBR, Campinas, v. 30, p. 149-163, 2008.

MONTAÑO, C. Terceiro setor e questão social: crítica ao padrão emergente de intervenção social. São Paulo: Cortez, 2002.

PAULANI, L. Brasil delivery: servidão financeira e estado de emergência econômico. São Paulo: Boitempo, 2008.

PERONI, V. M. V. As relações entre o público e o privado nas políticas educacionais no contexto da terceira via. Currículo sem Fronteiras.13(2). p. 234255, 2013.

POUlAntZAS, N. Poder Politico e Classes Sociais. São Paulo: Martins Fontes, 1977.

RAVITCH, D. Vida e morte do grande sistema escolar americano: como os testes padronizados e o modelo de mercado ameaçam a educação. Porto Alegre: Sulina, 2011.

SAVIANI, D. O Plano de Desenvolvimento da Educação: análise do projeto do MEC. Educação \& Sociedade, Campinas, v. 28, n. 100, p. 1231-1255, 2007.

SAVIANI, D. Sistema Nacional de Educação e Plano Nacional de Educação: significado, controvérsias e perspectivas. Campinas: Autores Associados, 2014.

SCHULTZ, T. O valor econômico da educação. Rio de Janeiro: Zahar, 1967.

SILVA, I. G. Democracia e Participação na "Reforma" do Estado. São Paulo: Cortez, 2003.

WOOD, E. M. Democracia contra capitalismo: a renovação do materialismo histórico. São Paulo: Boitempo, 2006.

WOOD, E. M. O império do Capital. São Paulo: Boitempo, 2014. 